http://jmscr.igmpublication.org/home/ ISSN (e)-2347-176x ISSN (p) 2455-0450 crossref DOI: https://dx.doi.org/10.18535/jmscr/v8i1.57

\title{
Role of Amniotic Membrane Transplantation in Brittle Cornea Syndrome-A Case Report
}

\author{
Authors \\ Dr Prasanta Kumar Nanda ${ }^{1}$, Dr Subhrakali Paramguru ${ }^{2}$ \\ ${ }^{1}$ HOD, Dept. of Ophthalmology, SCB Medical College, Cuttack \\ ${ }^{2}$ Post-Graduate Student, Dept. of Ophthalmology, SCM Medical College, Cuttack
}

\begin{abstract}
To evaluate the efficacy of multilayer amniotic membrane transplantation with fibrin glue in sclera fragility and recurrent corneal ulceration in Brittle Cornea Syndrome. It is suggested that reepithelialisation of a persistent epithelial defect in sclera and cornea is reduced by amniotic membrane transplantation in a patient of Brittle Cornea Syndrome leading to decrease in stromal inflammation and continued fibrosis, which is also aided by the combination of oxygenation and protection of the fragile epithelium by the amniotic membrane.
\end{abstract}

\section{Introduction}

Brittle Cornea Syndrome, Formerly Known as Ehler Danlos Syndrome Type 6B or Dysgenesis Mesodermalis Corneae at Sclerae is a type of connective tissue disorder that mainly affects eyes, joints and skin and inherited as autosomal recessive manner.

There are 2 types of Brittle Cornea Syndrome which are distinguished by the mutated gene causing them-BCS Type 1 associated with gene ZNF469 and BCS Type 2 associated with gene PRDM5, Terefore, effective molecular diagnosis is now available for affected patients and those at risk of being heterozygous carriers for BCS.

Brittle Cornea Syndrome includes

1. Ocular Symptom-
A. Recurrent Corneal Ulcers
B. Corneal Dystrophy
C. High Pathological Myopia
E. Early Onset Keratoconus \& Keratoglobus
F. Thin Cornea
G. Progressive Loss Of Corneal Stromal Depth
H. Retinal Detachment

Systemic Symptoms-

1. Hypercompliant Tympanic Membranes

2. Variable Skeletal Manifestations
A. Developmental dysplasia of hip
B. Muscular hypotony
C. Scoliosis \& Arachnodactyly
D. Small joint hyper-extensibility
E. Pes-planus \& Hallus-valgus
F. Mild contracture of fingers

3. Dermatological Manifestations
A. Soft, doughy skin
B. Hyper-elasticity
C. Mild abnormal scarring 


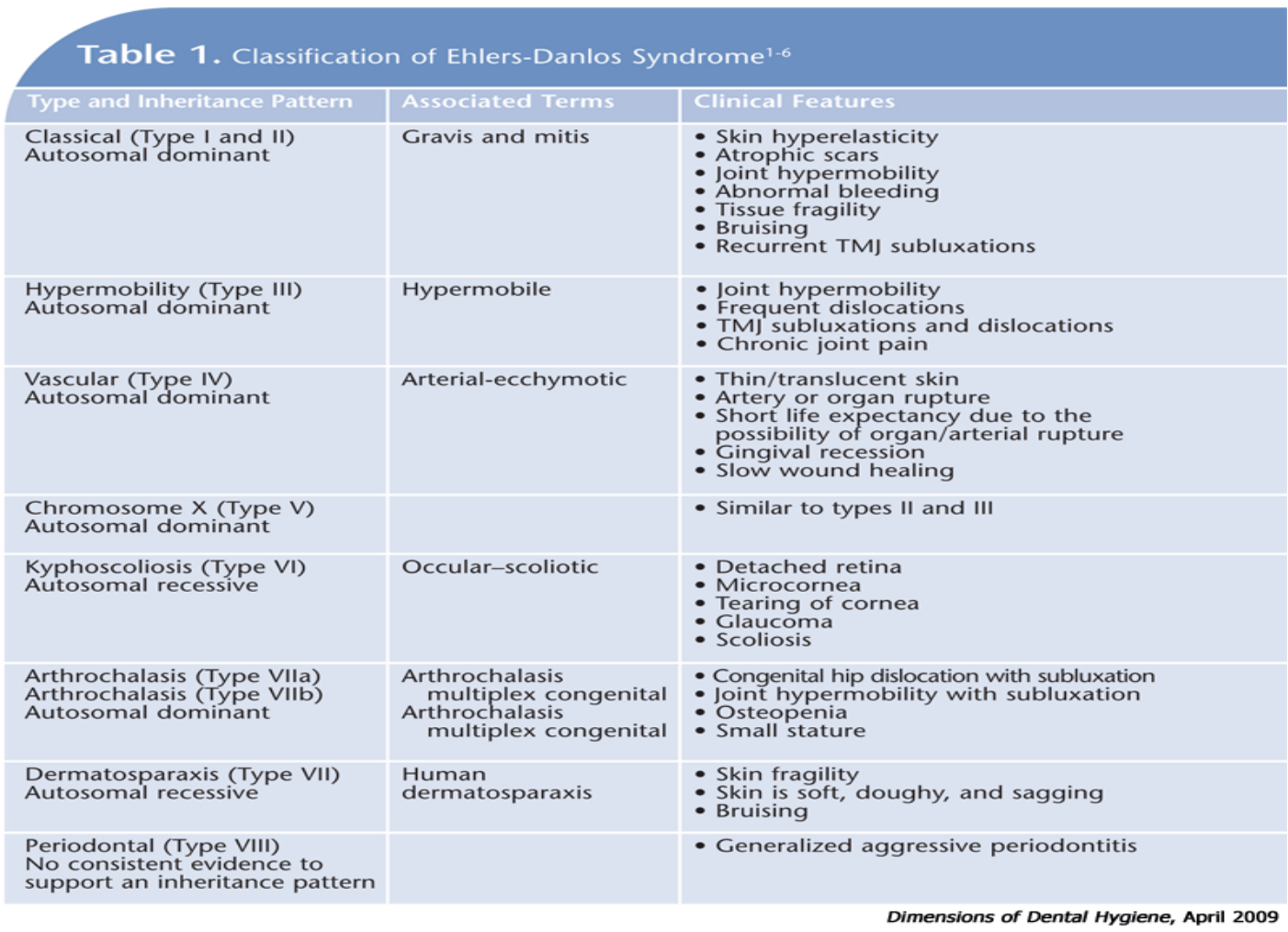

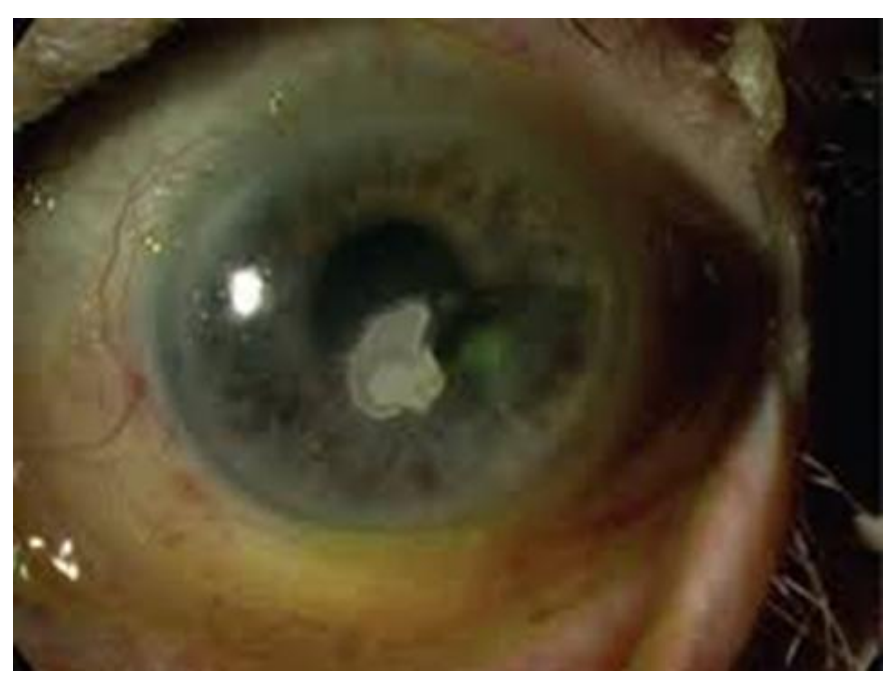

Figure 1: Corneal Ulcer with Scleral Fragility

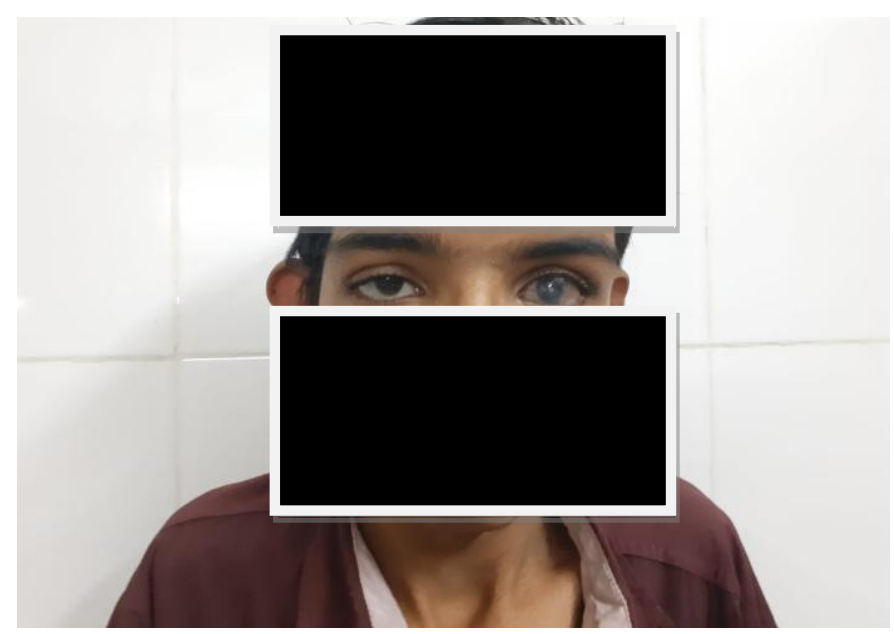

Figure: 2-Patient of Brittle Cornea Syndrome

\section{Materials \& Methods}

A 14 year old male patient with diagnosed EHLER-DANLOS SYNDROME was referred to SCB Medical College out-patient department of Ophthalmology for complete ocular evaluation and further assessment. He had a chief complaint of diminished vision in left eye since last 2 years, which was gradually progressive and not associated with any pain, photophobia, redness, swelling or lacrimation. On examination in slit lamp, the lids and ocular adnexa were normal, conjunctiva was mild chemosed, cornea is cloudy, hazy with an infective ulcer in superior temporal quadrant, sclera was blue in colour with increased fragility as proved by recurrent epithelial defects, anterior chamber was normal and pupil was reactive to both direct and concensual light reflex with no RAPD. Fudus of left eye showed a deep cup with cup disc ratio 0.8:1.

The case was initially treated with topical lubricants, antibiotics and other systemic treatment for reducing ocular morbidity. Amniotic membrane was obtained under sterile conditions after elective caeserian delivery and the woman was screened negative for HIV, HBsAg and HCV. Under all the sterile conditions after removal of 
the conjunctival extension up to the cornea and sub-conjunctival scarring up to the episcleral surface, amniotic membrane transplantation was done in operative room procedure.

The amniotic membrane was then secured to the corneal edge of the defect by interrupted suture.

Post operative care consists of preservative free prednisolone acetate $1 \%$ eye drop and chloramphenicol $0.5 \%$ both tappered off in 1 month.

\section{Results and Discussion}

In most of the patients the membrane dissolved in 2 months and epithelisation of the corneal ulcer apparently occurred underneath the membrane. Some patients underwent limbal transplantation after AMT who do not respond to AMT. This study noted successful sclera and later corneal transplantation of amniotic membrane along with long term stability. The most consistent finding here is a definite reduction in recurrent inflammation. In addition, amniotic membrane, soaked in an antibiotic solution before application showed a much higher concentration like that of a collagen shield. So it also reduces the long term use of topical antibiotics in early phase of epithelial defects in sclera and cornea in BCS. Recent advances have also shown that amniotic membrane contains Cystatin E, with complementary anti-viral properties \& HeatShock proteins with well known cytoprotective effects,

\section{Conclusion}

Multilayered amniotic membrane transplantation in cases of recurrent corneal ulceration and increased sceral fragility in BCS represents a very evolutionary method of treatment, not only to wound healing and preventing progressive melting of defective sclera and corneal epithelium, but also it has anti-oxidant property, cytoprotective roll and anti TNF alpha activity and collagen sparaing effect due to inhibitory control over MMP 2 \& 9.

\section{References}

1. Van herendeal BJ, Micro anatomy of human amniotic membrane

2. Akle CA Immunogenesity of human amniotic epithelial cells after transfer into volunteers

3. Ward DJ, Bennet JP,the long term results of use of human amnion in epithelial ulcers

4. Faulk WP, Mathews RN Human amnion as an adjunctive to wound healing

5. Trefold JD, The amnion in surgery, past and present

6. Shimazaki J,Tsubota K,Transplantation of AMG for patients with recurrent pterygium

7. Tsuba K,Toda I,S aito H, Reconstruction of the corneal epithelium by AMT for severe ocular surface disorders. 